\title{
GENRE BASED TRANSLATION: A STUDY OF NOTICEMENTS IN BALI TOURISM OBJECTS
}

\author{
Ihyak Mustofa \\ ihyakm@yahoo.com \\ English Department of Universitas Panca Marga \\ Jl. Yos Sudarso No. 107, Probolinggo, Indonesia 67271
}

\begin{abstract}
This study is genre based translation. This article is aimed to explore 4 texts and its translations in notice boards of tourism objects in Bali. The first is the notice board found on Kuta Beach. The second is in the Nusa Dua beach, Denpasar. The third is in Dreamland, Pecatu. The last is found in Pura Gunung Raung, Gianyar. Then, to find the recommendations based on the finding to the translator. There are three kinds of mistakes found in those texts. They are: word choices, explicitations, and Addition/omission.
\end{abstract}

Keywords: Translation, Linguistics, Genre, SFL, NR, ESP.

\section{Introduction}

Translation is transferring message from one language (source language) to another language (target language). The purpose of translating is to convey the original tone and intent of the message, taking into account cultural and regional differences between source and target language.

Nowadays, the study about translation is developed. One of the new forms of translation study is genre based translation. It is a translation which is created based on specific use of language. There are three approaches that used in genre studies namely: Systemic Functional Linguistics (SFL), the New Rhetoric (NR) genre theory, and English Specific Purposes (ESP). This study is applied Systemic Functional Linguistic as the approach to analysis the genre, because the object of this study is relevant to the approach. It is focused on the internal linguistic feature rather than the regularly activities.

In relation to this study, the tourism industry has shown sustained growth in both revenues and number of tourists, and has left broad economic, social, cultural and environmental footprints reaching almost every part of the world. Indonesia as the development country, one of the primary motivations for a country to promote itself as a 
tourism destination is the expected economic improvement. Thus, the sign or the directions should give the relevant information to the tourists, so that they can enjoy anything the want.

One of the oldest methods used in delivering latest information or to make announcements in tourism object is by using the notice board. It is normally made of wooden framed board and it displayed big fonts to ease the readers who read it. According to Osamor et al. (2007), the wooden notice board is a flat solid object placed at strategic positions, makes it an object with notices and posters on it. Furthermore, the information in the notice is more relevant rather than in the other notices, because it is usually removed by the time. Therefore, the noticements in tourism objects are relevant object to be researched.

This article is aimed to explore 4 texts and its translations in notice boards of tourism objects in Bali. The first is the notice board found on Kuta Beach. The second is in the Nusa Dua beach, Denpasar. The third is in Dreamland, Pecatu. The last is found in Pura Gunung Raung, Gianyar. Then, to find the recommendations based on the finding for the translator. Theoritical insights were drawn from Schematic Structures proposed by Martin (1992).

\section{Literature Review}

Some works are considered as relevant to this study. The first is Li Yongqing (2013) who studied Genre based translation in hotel promotional text in Malaysia. The purpose of the study is to use a genre approach to explain the use of advertising language in Malaysia hotel advertisements in attaining their objectives. The study also examines the way of the advertisements were written. The Five-Move structure for hotel advertisements proposed by Gu Xiangfen (2008) has been adopted to analyze a sample of 20 Malaysia hotel advertisements. The study also looks into other aspects of the texts, such as the communicative purposes and the linguistic features.

The second is Carmen (2006) who studied genre based translation based on the role of instruction. This study seeks to validate the use of translation as a methodological procedure that facilitates learners' interpretation of professional writing practices. It mainly contend that translation activities can become an adequate linguistic input in the teaching of professional written genres as regards the analysis of the linguistic, rhetorical and social components of these genres.

The third is Safnil (2013). The main purpose of the study was to search for the occurrence of communicative and subcommunicative units and to identify the linguistic features commonly used by the authors to realize the communicative and subcommunicative units. Three groups of English RAs by Indonesian speakers were chosen for this study: 10 RAs from engineering science, ten from science and ten from medical science journals. This study used genre-based method to investigate the communicative units in the text by using Swales' CARS as a model. The findings confirm those of previous relevant studies that discourse styles and linguistic features of English 
RA introductions by Indo- nesian speakers are different from the ones by English native speakers.

The fourth is Ornella (2011). This study presents an analysis of abstracts from research articles found in Linguistics and Translation Studies journals. It first presents some theoretical background on discourse community and genre analysis, then it shows the analysis carried out on 18 abstracts, 6 written in English, 6 in Portu- guese and 6 being their translations into English. The analysis aims at verifying whether the rhetorical patterns of organizations and the moves found in abstracts coincide with those proposed by Swales (1993) in his study of research articles and introductions. Besides, it intends to identify the verb tenses and voice preferably used in this kind of text as well as mechanisms used to indicate presence or absence of the writer in the text. The analysis reveals that the rhetorical patterns and some moves proposed by Swales are found in abstracts, though not in the same order. It also shows a high occurrence of present simple tense and active voice in all moves and passive voice only occasionally. It argues that the absence of the writer is a distinctive feature of scientific discourse and it is obtained by means of passive voice and typical statements used as resources to avoid the use of personal pronouns.

The fifth is Anabel (2013). This article describes an action research project on multilingual management and translation of court documents developed by the GENTT research group, which postulates that the notions of 'textual genre', 'genre system' and 'meta-genre' can be powerful tools for accessing and 'reusing' the linguistic and extra-linguistic information technical writers and translators need to manage specialised communication. To validate this hypothesis the criminal court genre systems of four countries (Germany, Spain, France and the United Kingdom) have been analysed and described from a legal-conceptual, discursive-textual and terminological perspective. The results of this contrastive analysis have been used as the basis for creating translation resources (both conceptual and linguistic), which have been organised into an online platform for translators of court documents. This platform is conceived as a knowledge system which will permit the 'reusability' of electronic translation resources. Our approach presents an integrative methodology for research into legal translation.

Based on those studies, there are some novelties that can be applied in this study.

1. Genre analysis that used noticement as the object is still rare.

2. A translation study which is based on genre rarely observed or researched. This study can be one of references to study genre based translation.

3. The Genre based translation study about noticement in tourism industry is not be researched yet.

\section{Discussion}

\section{A. Genre Analysis on SFL approach}

\section{Macro Genre}


In Systemic Functional Linguistic (SFL) approach, the Macro genre of the data is belonged to information text. Macro genre stands in for the idea of "complex" or "secondary" genres that might involve other multiple embedded genres. The SFL approach avoids the difficulty of talking about "complex" or combined genre as separate from other genre types by only recognizing a limited set of genre as such. (Hyland, 2002: 123) defines "texts which combine more fundamental element genres such as recounts, narratives, explanations and so on". These sets of acknowledged genres, such as the recount, are then combined to create all other text types as macro genres.

\section{a. Micro Genre}

The micro genre of these data is classified as noticement text. Martin and Rose (2003; 2007) proposed that micro genres are independent, elaborating, explaining, and projecting each other within macro genres. Furthermore, the micro genre can develop the view of macro genre. Then, the structure of micro genre can be combined each other, for example: recount text can be combined with description and report, report can be combined with exemplum or discussion.

\section{b. Schematic Structure}

The schematic structure is one of important genre analysis system in systemic functional linguistics theory developed by Martin (1992). Kathpalia (1992) suggests that though this approach is considered to be an extension and a revision of Hasan's Generic Structure Potential approach, the difference between the two concepts lies in their views of genre and register and the position and relationship between these two concepts.

The staging (steps) in both approaches is influenced by the social context (Martin, 1992). The difference however, lies in the choices of field, tenor, and mode. Hasan sees field, tenor and mode to be realized by schematic structure, while for Martin schematic structure is realized through the choices of field, tenor, and mode.

The schematic structure is also applied to this study. Field of the data is to give information or to prohibit doing something. Tenor of the data is the text producers are informing the readers, and the mode of the data is written text in a notice board.

c. Text structure and Lexicogrammar

In the perspective of SFL, language is perceived as a system of choices by which writers can communicate certain functions, namely expressing their experiences of the world (experiencal metafunction), interacting with others (interpersonal metafunction), and creating coherent messages (textual metafunction). These contextual features influence the patterns of texts in terms of text structures and lexico-grammatical patterns.

The language features in notice board tend to be simple. The simpler sentence makes the reader understand easily. Next, the font of the text is bigger and clearer than the other information text. This makes the information can be seen from long distance and people do not necessary to come closer to the notice board. 


\section{Translation Analysis}

a. Word choices

Word choice is the choice and the use of word which is the first to be affected in translation. The translator should think about the meaning carefully and find the corresponding expression in target language. One of the factors that may influence the word choice is different cultural background. People in different background may have different recognition in one thing. If the translator does not pay attention to this aspect, he may cause misunderstanding.

\section{For Example:}

\section{Data 1.}

SL: Mandilah selalu diantara dua bendera merah kuning

TL: Always swim between two yellow red flags

The word "mandi" is translated into "swim". In Bahasa Indonesia, "mandi" refers to an activity of cleaning body with water, it can be done in bathroom, river, beach, etc. However, in English, the word "swim" has different meaning. It is an activity that moves the body through water by using arms, legs, a tail etc. Thus, the message of the source language does not delivered well, because there is a wrong word choice.

b. Explicitation

Explicitaion is a term to describe or explain more about a word. According to Klaudy (2008), there are four types of explicitation. The first is obligatory explicitation. It is caused by lexicogrammatical differences between source and target language. The second is optional explicitation. It is caused by differences in stylistic preferences between source and target language. Next, Pragmatic explicitation is an explicitation which is caused by differences cultural or world knowledge shared by members of source and target language communities. The last is translated in-herent explicitation. It is caused by the nature of the translation process itself.

\section{For Example:}

Data 2

SL: Terima kasih untuk menjaga kesucian pantai ini

TL: Thank you for respecting our Balinese culture

The translator wanted to explicit the word "kesucian pantai ini". The Balinese have a culture to maintain the God's creation, in this case, the beach. The translator has made a mistake because he only describes it by the words "our Balinese culture". Thus, the explicitation makes the message changed.

c. Addition / Omission

In translating text, translator sometimes adding or omitting words. As long as it does not change the message of the text, it is acceptable. There are some factors that 
affect the occurrence of addition such as specification purpose, amplification from implicit to explicit status, addition of categories. Next, the factors that affect the occurrence of omission, those are omitting the information, omitting specification of reference and omitting conjunction or transitional.

\section{For Example:}

\section{Data 1}

SL: Mohon untuk tidak melakukan kegiatan seksual di area tempat ini

TL: Please respect and do not commit sexual activity in this area

The word "respect" is an addition. It changed the message, because in the source language, there is no word that talked about respect. Then the word "respect" should not be added.

This study has shown that the noticements in tourism objects in Bali have conventions. First, they have simple forms in giving information. They are only consisted of the head and the content. The purpose is to ease the reader to comprehend the noticement. Next, the font of the noticement is big and the color is contrast to the background of the noticements. The purpose is to make the information clearer and the readers do not need to come closer to understand it.

The mistaken translation from source language (Bahasa Indonesia) to target language (English) has a pattern:

\begin{tabular}{llll}
\hline & Word Choices & Explicitations & Addition / Omission \\
\hline Data 1 & 1 & 1 & 1 \\
Data 2 & 2 & 1 & 1 \\
Data 3 & 1 & & \\
Data 4 & 1 & 1 & \\
\hline
\end{tabular}

The Data 1 showed that there is a mistake in word choice, an explicitation, and an addition. In the Data 2, there are 2 wrong word choices, a explicitation and an addition. Next, the Data 3 showed that only wrong word choice which occurred. The last, the Data 4 showed that there is a wrong word choice and an explicitation.

Wrong word choice is main problem that happened on noticements in Bali tourism object. It may be caused by the culture of the translator. He does not pay attention to the cultural aspect in English. Then, that can make the readers misunderstand to the message inside the noticements.

Explicitation is the second problem. Third of four of the data are had the problem. It is caused by the different comprehension about the specific thing. Then, the translator may mistranslate the word. 
Addition / omission also become a problem in the noticements. Some texts are use this term, but it changed the message. Addition or omission is allowed in translating, but it has to maintain the message of the source language.

\section{Conclusion}

After looking closely at the noticement in Bali tourism objects, there are some conclusions that can be drawn as follows:

1. The noticements in Bali tourism objects have a convention in structure and font. The structure is head and content. The font is bigger than other text and the colour is contrasted to the background.

2. The text in the noticements tends to be simple.

In relation to the translation in the noticements, there are also some recommendations to the translator.

4. The translator should pay attention to the cultural background of the readers.

5. The translators should use the appropriate word in translating some cultural terms

6. In correlation to explicitations, the translators should describe a terms properly and clearly

7. The translators should pay attention to the message when adding or omitting word in translating noticement text.

\section{References}

Anabel Borja Albi. 2013. A genre analysis approach to the study of the translation of court documents. Journal of Jaume I, Spain.

Carmen. 2011. A Genre-oriented Translation-based Instruction to Professional Communication. Journal. BIBLID 1133-1127 (2006) p. 271-290.

Hyland. 2002. Teaching and Researching Writing. Britain: pearson Education limited.

Kathpalia. 1992. A Genre analysis of promotional text. Unpublished PhD thesis. National University Singapore.

Martin and Rose. 2007. Working With Discourse. Continum: London.

Martin, J. R . 1992. A contextual theory of Language, in the power of literacy-a genre approach to teaching writing. Pittsburgh: Pittsburgh University Press.

Mustofa, I., \& Nababan, M. R. (2019). Male Characters' Expressive Speech Act on Romantic Speech Events in New Moon. International Journal of Linguistics, Literature and Translation.

Ornella Inês Pezzini. 2011. Genre Analysis and Translation - An Investigation of Abstracts of Research Articles in Two Languages. Journal.Universidade Federal de Santa Catarina. Vol: 22-2011.

Osamor, V. C., Aloba O. S. \& Osamor, I. P. (2007). From Wooden to Digital Notice Board (DNB): Design and Implementation for University Administration, International Journal of Electrical \& Computer Sciences, 10(2), 79.

Safnill. 2011. a genre-based analysis on the introductions of research articles written by indonesian academics. TEFLIN Journal, Volume 24, Number 2, July 2013. 
Swales, J. M. 1993. Genre analysis: English in academic and research settings. Cambridge University Press, Cambridge.

Yongqin Li .2013.a Genre Based Analysis of Hotel Advertisements. Thesis. Universiti of Malaya. Kuala Lumpur.

Cite: Mustofa, I. (2020). Genre Based Translation: A Study of Noticements in Bali Tourism Objects. Diadikasia Journal, 1(1), 85-92. https://doi.org/10.21428/8c841009.b655dodf 